\section{ADDRESS IN OBSTETRICS}

BY

WILLIAM J. SMYLY, M.D., F.R.C.P.I.,

Vice-President of the Royal College of Physicians in Ireland ; Gynæcologist to the Adelaide Hospital, Dublin.

At the Annual Meeting of the British Medical Association at Ipswich, July-August, 1900.

THE MATERNAL MORTALITY IN CHILDBED. As the century draws to its close a retrospect is not only excusable but advisable. At such a time we naturally pause to consider the way we have come, how we differ from our predecessors, and what we have gained in these hundred eventful years. Periodical literature is full of such retrospects : our modes of life ; the discoveries of science ; means of locomotion ; and methods of warfare, are contrasted with those of 1800 , and the verdict is that in the present century a greater advance has been achieved than in all that preceded it. Medicine and surgery have shared to the full in the advances of this wonderful age; and it now falls to my lot to show how midwifery has participated in the general improvement.

In considering the history of midwifery many subjects suggest themselves which would offer ample material for an address in obstetrics.

The struggle between science and nescience, as represented by medical practitioners and midwives, commenced in the sixteenth century, was fought in every civilised country with varying fortune, and continues in our own time to be a burning question.

The contest between Radicals and Conservatives, or those who incline to operative interference and those who rely more exclusively on Nature, are as fully represented amongst us here to-day as they were in the days of Levret and Smellie, of Boër and Osiander.

The rise and fall of lying-in hospitals, their almost total extincton and resuscitation in our own time, has no parallel in medical history. To have closed these institutions would have been the sealing of the fountain of knowledge at its very source, yet few could deny that Simpson was actuated by the highest motives of humanity in the campaign which he carried on against them.

The development of obstetrical literature, the origin and development of obstetrical and gynæcological societies, national associations, and international congresses, each and all of these would have offered ample material. I have preferred, however, a subject much more familiar, and often dealt with, but at the same time of much greater importance than any other that could be chosen, namely, the maternal mortality in childbed.

The Failures of the Earlier Part of the Chntury.

The history of midwifery is a long one, extending back to the earliest times. The Hebrew scriptures abound in obstetrics, and midwives as a class are distinctly mentioned therein. A knowledge of the art existed amongst the Indians, Greeks, and Romans, and later amongst the Arabians, but scientific midwifery may be said to have commenced with Ambroise Pare in the sixteenth century. During the intervening years up to the present time it has been advanced by ardent and zealous investigators, many of whose names can never be forgotten-Mauriceau, Deventer, the Chamberlens, Levret, Baudelocque, Sir Fielding Ould, Smellie, William Hunter, Boër, Naegele, the Ramsbothams, Sir James Simpson, Mathews Duncan, Robert Barnes, and a host of others too numerous to mention. But in considering the improvement in the death-rate in childbed we need not go back many years. It did not take place gradually as the light of science slowly dawned upon our art, but occurred suddenly in the seventh decade of the present century. The observers of the past pursued their object in the face of failure little short of disaster ; their zeal and perseverance were not rewarded by success, but, on the contrary, the more famous the professor 4 the wider his field of observation, the greater his industry and the more searching his investigations, the worse were his results. In the first half of the present century the mortality amongst parturient women, especially in hospitals, was probably greater than in any other period of the world's history.

The Dfcline of Mortality in Lying-in Hospitals.

Towards the close of the Seventies, however, a sudden and salutary change took place. In the Paris Maternity, for example, the mortality dropped in one year from 8 per cent. to 4 per cent, and in 1881 to 1 per cent., and has since improved, and in all the hospitals of Europe a similar change occurred. As to private practice, however, I am not able to give any facts founded upon reliable statistics. Dr. Mathews Duncan in his monograph on mortality in childbed published in 1870 deliberately stated that "all attempts at ascertaining scientifically the mortality in childbed must be given up." Dr. McClintock also said about the eame time: "With our great registering machinery all at work we cannot find out what is the mortality of childbed in London. For my part I think that obstetrical common sense will be well contented if the true childbed mortality of modern London is at all less than in London of 1660 . It is very doubtful if it is even now as low as $\mathrm{I}$ in 107."

Mathews Duncan after careful investigation agreed with McClintock that the mortality in private practice was not less than $I$ in 120 . His own results were 1 in 105 , McClintock's 1 in 108 , Dr. Churchill's $\mathrm{I}$ in $\mathrm{I} 59$. In the face of such results in the hands of the best men it is idle to talk of the general mortality having been at that time is per 10,000. In comparing the results, therefore, of modern with ancient practice, we must confine ourselves to hospital statistics, and I have no doubt that the results in private practice are a faithful reflection, perhaps some years later, of the teaching in those insti. tutions.

Statistics of the Rotunda Hospital.

I will take as an example for the purpose of contrasting the results obtained in the Rotunda Hospital during Dr. Johnston's Mastership, I870-1876, and the seven years, I890-1896. I have chosen Dr. Johnston's report because it was the period immediately preceding the introduction of antiseptics, and because his results were considered at the time to have been remarkably good. During the first period (1870-1876) 8,092 women were delivered in the hospital, of whom 169 died, or 1 in 45.5 . During the second period (1890-1896) 9085 , with 50 deaths, or $x$ in 181.7 ; showing a saving of about 200 maternal lives in every 10,000 deliveries.

If we adopt the classification of the Registrar-General the deaths appear as due to :

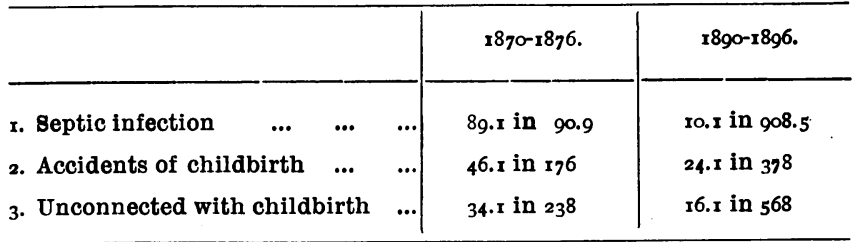

Similar results are shown by hospitals generally. It is evident, therefore, that in hospitals at least a marked improvement has taken place during the past quarter of the century in all the three groups: death from puerperal fever, accidents of labour, and other causes.

Puerperal Fryer or Septic Infection.

The greatest improvement is observable in this group, and I shall offer no apology for dwelling at length upon the way in which it has been brought about.

In the beginning of the century obstetricians were ignorant of the nature of this, the chief cause of childbed mortality, and were helpless either to prevent or cure it. Epidemics became more frequent and more virulent; and obstetricians endeavoured by clinical observation and post-mortem examina. tion to discover its nature; but unfortunately both these roads to knowledge were pursued by the same individuals, and with disastrous results. In Paris, Cruveilhier, the most illustrious of French pathologists, was appointed Physician to the Maternity; he multiplied his researches, and at the same [2067] 
time the mortality in that institution increased. Little of value was added to our knowledge by these investigations, and even in $1872 \mathrm{Dr}$. Churchill reflected the general ignorance when he published in the sixth edition of his well-known work his opinion that puerperal fever was due to mental emotion, cold, putrefaction of portions of retained placenta, gastro.enteric irritation, the state of the atmo phere, epidemic influences, and contagion. With regard to the latter he felt compelled, by the evidence, to admit the possibility of its being conveyed and communicated or excited by those who had attended midwifery cases after being employed in dissection or post-mortem examination, or who were murh in contact with fever patients, but in all other cases he attributed its occurrence to epidemic influence.

It is pleasant to turn from this general ignorance,"and mark the first beams of the dawning day.

Dr. White of Manchester.

Towards the end of the last century a remarkable work on the management of pregnant and lying-in women was published by Dr. White, a surgeon practising in Manchester. In that work, published in 179I, he attributed puerperal fever to the absorption of putrid matter by the lymphatics and vessels of the womb. To this conclusion he arrived by observing the similarity, in causation and symptoms, to putrefactions occurring in other parts of the body. In chronic abscess, for example, dangerous symptoms, similar to those of puerperal fever, set in after it had been opened and the air had gained admission; so also in childbed, fever did not occur until after the child was born. He further observed that when a putrid wound was cleansed, the symptoms abated; and that where the disease was so situated that it could be removed by amputation they entirely disappeared-and from this he concluded that absorption of putrid matter was the cause of puerperal fever.

His treatment was therefore directed towards the prevention of putrefaction and elimination of putrid matter should it have already formed. To these ends he advocated thorough ventilation, cleanliness, and drainage. Foul stagnated air, human effluvia, heat and moisture, were to be avoided. Free and even cold air should pervade the apartment, and clean linen be supplied every day. The lochia, if permitted to stagnate in the vagina, would soon become putrid, for, he said, it is well known that the mildest humours in the human body, if suffered to stagnate, become acrid as soon as the air has access to them. He therefore encouraged his patients to sit up several times a day, and even to leave their beds, so as to prevent a lodging of offending matter either in the vagina, uterus, intestines, or bladder. Perhaps the most remarkable statement in this work is the following: "I must not omit to mention," he says, "the good effects I have experienced from emollient or antiseptic injections into the uterus by means of a large ivory syringe or an elastic vegetable bottle in those cases where the lochia have become acrid or putrid, and by being absorbed into the circulation have served as a constant fomes to the disease. I have by this means known the fever much assuaged, and in many cases wholly extinguished, for though the quantity of the lochia is not to be much regarded, the quality of this discharge is a matter of infinite importance." One cannot but wonder at White's independence of opinion and the general correctness of his views. He was only a provincial surgeon, yet he did not shrink from stigmatising the teaching of the obstetric world of his day " as a set of pernicious maxims and opinions, built upon ignorance, and supported by prejudice and obstinacy." With truth he declared that the slightest remark drawn from real observation is of more utility than the most extensive theory of causes drawn from hypothesis alone. Ignorance, prejudice, obstinacy ! these were the forces against which he combated and, alas! in vain, nor for fifty years after did another champion take the field against them, to perish in the encounter.

Ignaz Philipp Semmelweis.

That champion was Ignaz Philipp Semmelweis. With what feelings of regret and shame should we recall his name! Not long ago obstetricians in every land combined to raise a memorial to it. But during his sad life no such recognition of his virtues smoothed his thorny road. Of us it may well be said, "Your fathers killed the prophets, and ye build their sepulchres." Had they but learned of him, instead of ridiculing, opposing, and neglecting him, how different would have been the history of obstetrics in the past half century ! Obstetricians would have led the van, and have taught the surgeons antiseptic methods; but the contrary has been the case, and surgeons have taught us what Semmelweis strove to teach our fathers twenty years before. What an amount of humun life would have thus been saved, what untold anguish and remorse might there have been avoided; but ignorance, prejudice, and obstinacy prevailed.

In 1846 Semmelweis, a young man of 28 , was appointed assistant to Professor Klein in the maternity department of the Vienna Hospital. Not only was his sensitive nature shocked by the fearful mortality which prevailed in the department attended by the students, but his observant mind was also struck by the more favourable results obtained in the neighbouring department reserved for the instruction of pupil midwives. Reviewing the history of the institution, he found that from 1784 to 1822 the physicians connected with it performed no post-mortem examinations, and that the average mortality during that period was 1.25 per cent.; from 1825 to 1833 post-mortem examinations were made, and the mortality increased to 5.3 per cent. In 1839 the clinic was divided into two departments, and the second was reserved for pupil midwives; the mortality in it fell at once to 2.6 per cent., whilst in the other, where the students attended, it increased to 9.5 per cent., and this proportion remained the same for the five succeeding years, excepting the years $1841-43$, when during an epidemic of twenty months' duration the mortality in the first department averaged 16 per cent., and at one time rose even to 31.3 per cent. At the post-mortem examination of his colleague Kollitshka, who died of septic poisoning, Semmelweis was 80 struck by the similarity between the appearances in that case, and in the patients who died from puerperal fever, that he concluded that the cause must be the same in both-namely, an infection from without, due to the transportation of cadaveric poison by the fingers of the attendants, and he directed that before attending lying-in women they should wash their hands in a solution of chloride of lime. The mortality at once sank to 3.05 per cent. Subsequently, however, he formed the opinion that any organic substance in course of putrefaction, and especially the discharges of women with septic diseases; and even air charged with putrefactive matter might cause fever; and from this time the hands were disinfected in every case, as well as instruments, and the materials used in cleansing the patients, and the sick were separated from the healthy. The mortality fell to 1.27 per cent. Having been defeated, by the intrigues of his colleagues, whose animosity he had aroused, in his candidature for a professorship in Vienna, he went to Buda Pesth, where he filled the office of Senior Physician to the Rochus Hospital for a period of six years, and under his administration the mortality in that institution averaged only 0.85 per cent. Having again been unsuccessful in his candidature for the Professorship in Prague, he retired from practice and devoted his energies to publishing his great discovery in a work on the Nature and Prophylaxis of Puerperal Infection.

The story of Archimedes springing from his bath and rushing forth shouting " Eureka, eureka!" is a comedy in science, but the history of this man urging his great discovery upon those who received it with indifference or hostility and ridi. cule; stopping the passers in the streets to impress on them the importance of life-saving truths which they would not receive-this forms a tragedy fit to make the angels weep. In these endeavours he fretted and fumed his life away, until at last reason departed and he was consigned to the lunatic asplum in Vienna, where four years later he died from septic poisoning, that very disease which he spent his life in combating. Semmelweis discovered the same truth as White had done fifty years before that putrefaction was the cause of puerperal fever, but he added another and much more importan $\hat{\imath}$ one, namely, that the disease could be conveyed to the patient by her attendants. These two methods he termed auto- and hetero-infection.

\section{ANTISEPTICS.}

Long before Semmelweis fretted himself into insanity he might have discovered, had he had patience to observe it, that the seed he was sowing had already taken root and would soon 
bear abundant fruit. Michaelis and Lange had adopted his views with success. Simpson warmly advocated them in this country and pointed out their applicability to operative surgery. The wonderful discoveries of Pasteur were published two years before his death, and these discoveries not only confirmed his views, but placed them upon a firm scientific footing. Lister was already in the field in 1864 and astonished the world by the wonders of antiseptic surgery. But it was not until 1870 that antiseptic principles were applied to obstetric practice, and practically banished puerperal fever from our hospitals. Stadfeld, Bishoff, Fritsch, Schroeder, Breisky, Lucas-Championnière were the pioneers in this movement. At first Listerian methods were closely followed, but not only was the original system too cumbrous for general practice, but it was soon discovered that many of its details might with advantage be abandoned.

\section{The Douche}

The spray was replaced by the douche, and the vagira was douched with antiseptic fluids before and after every labour. Soon the uterus was also included in the process and prophylactic douching reached its climax when permanent irrigation or instillation was introduced by Schücking. Soon, however, serious accidents and even deaths, the result of the douche, began to multiply. These were due to injection of air and antiseptic fluids into the veins. In some cases the uterus was perforated and poisonous fluids injected into the peritoneal cavity, but, worst of all, the douche proved to be a cause of the very disease which it was intended to prevent. Runge described an epidemic in the Charite Hospital, Berlin, in which the mortality remained at 38 per cent. so long as prophylactic douching was employed, but immediately sank to o.39 per cent. upon its abandonment. Breisky reported a similar experience. In a series of papers in the Archiv für Gynceologie Professor Leopold clearly showed that by thoroughly disinfecting the external parts and avoiding unnecessary examinations far better results were obtainable than by prophylactic douching. In 1888 , however, in consequence of tine results of bacteriological examination of vaginal discharges he returned to vaginal douching; immediately the morbidity increased by 3 per cent. The next year he again gave up the irrigator, and this was followed by an improvement of 9 per cent. I need hardly explain that by morbidity is meant 3 rise of temperature even once to $100.4^{\circ} \mathrm{F}$. The whole question of the value of prophylactic douching-and it can hardly be said to have been finally settled even yet, for many leading obstetricians both in this country and abroad still resort to it-resolves itself into the probability or even possibility of auto-infection. That the vaginal discharge often contains germs, many of which are apparently septic or saprophytic, is undeniable, but are these germs really dangerous to the patient, and can they be removed by antiseptic measures? These are the two important questions. In 1888, Winter examined the discharge in twenty women, and found twentyseven varieties of micro organisms. In 50 per cent. of these women he found streptococci and various saprophytes, though in an attenuated condition. In 1890 Streffeck made a similar series of examinations, and found pathological organisms in nearly the same proportion of cases. He therefore advocated vaginal douching. Döderlein's investigations in the same direction led him to classify discharges as normal and pathological. The normal were of a creamy consistence, intensely acid in reaction, and contained usually a pure culture of an organism which he named the vaginal bacillus, and to which he attributed the acidity of the discharge. The pathological discharge was of thinner consistence, often puriform in appearance, was feebly acid neutral or even alkaline in reaction and contained a great variety of micro-organisms, some of which were dangerous. The normal discharge he discovered to be not only innocuous but actually antiseptic. He injected into the vagina of a virgin a culture of staphylococcus, and found that in the course of forty-eight hours this organism had entirely disappeared. From these and other experiments he concluded that where the discharge was normal vaginal douching was unnecessary, but on the contrary where it was pathological, a thorough disinfection of the canal was imperative. Döderlein's investigations were repeated in the same clinic in Leipzig by Krönig. In 568 per cent. he found the discharge normal, in 43.2 pathological; but in none of these was it either neutral or alkaline in reaction. He agreed with Döderlein as to the antiseptic properties of the normal discharge, but denied that it was due to the vaginal bacillus, and found on the contrary that the so-called pathological discharges which did not contain the bacillus also possessed a similar bactericidal property. He injected cultures of the bacillus pyocyaneus, staphylococcus doré, and even streptococcus pyogenes into the vagina, and found that they were all eliminated within twenty-four hours. A most important observation with regard to douching was that in cases in which, after injecting the micro-organisms, he at once thoroughly scrubbed out the vagina with a I per cent. solution of corrosive sublimate or lysol, they had not entirely disappeared at the end of 36 hours. The douche, therefore, not only failed to dislodge them, but so altered or removed the natural discharges, that for at least 12 hours the normal bactericidal action of the vagina was annihilated. The result of these investigations was that vaginal prophylactic douching was altogether abolished in the Leipzig Hospital, with the result that morbidity was thereby reduced ro per cent.; the gravity also of the infected cases was less; so that the number of women who were detained in the hospital beyond the tenth day was reduced by one-half. Some of the most distinguished French accoucheurs, whilst admitting the importance of the facts I have mentioned, still adhere to the prophylactic douche, and with good results, but at the same time they point out the absolute necessity for observing perfect asepsis; the external parts of the patient, the hands of the operator, instruments, and even the water must be absolutely pure. When we remember, however, that this operation, if carried: out two or three times every day must necessarily be entrusted to a nurse, I have no hesitation in saying that the preservation of perfect asepsis, or anything approaching it, will be found in general practice to be absolutely impossible. Where are such nurses to be found? In these countries they are certainly rare, and from personal experience I feel certain that routine douching has been productive of much more harm than good.

The Hands of the Attendant.

We now come to the attendant, and our attention may be concentrated upon his hands. The teaching of Semmelweis and Sir James Simpson that infection is carried chiefly by the hands of attendants is now the generally accepted opinion. If I were to state that where there had been no handling there would be no septic infection I should not be very far from the truth. Leopold has clearly proved that patients who deliver themselves without any vaginal interference make a better convalescence than those who have been examined even with the most scrupulous antiseptic precautions. Experience therefore proves-what bacteriological investigation would lead us to expect-that an absolutely aseptic condition of the hands cannot be insured by any known process, and from this we learn:

I. To avoid as far as possible septic contamination.

2. To spare no pains to render our hands as innocuous as possible; and

3. To restrict local interference within the narrowest bounds.

The last of these includes not only unnecessary operative interference, but also needless vaginal examinations. We can limit the numbers of such examinations best by substituting for them external manipulations; and, next to antiseptics, I consider this to be the most important advance in modern midwifery. By whom it was introduced or when I know not, but its systematisation and popularity we owe to Pinard, Credé, and Leopold. In 1888 Credé wrote as follows: "Even the simplest manipulation may cause infection. It should therefore be laid down and taught as a fundamental principle that internal examination of parturient women should be altogether avoided or restricted within the narrowest possible limits ; it can be very well replaced by external examination. To instruct their pupils as thoroughly as possible in this method is the present and future duty of teaching institutions."

Diagnosis by External Examination.

By external examination we can tell whether the woman is pregnant or not, and the period to which the pregnancy has 
advanced, the presentation and position of the fotus; whether it be living, dying or dead, and whether there be one or more children in the uterus. We can also tell whether she is actually in labour or not; and its course and progress may be followed with accuracy. Pelvic deformity is suggested by pendulous abdomen, abnormal mobility, and obliquity of the uterns, especially in primiparæ and in the latter also, excepting hydramnios, hydrocephalic fotus, and plurality of children, all of which may be diagnosed by this method, it is an ominous sign, where labour has actually commenced, to find the head still above the brim; the way in which it enters the cavity is also characteristic. In prolonged labours danger to the mother is indicated by thickening of the upper and thinning of the lower uterine segments ; the elevation of the contraction ring and the prominence of one or both round ligaments. External examination is equally useful in the third stage of labour, and its proper conduction depends upon it.

The external examination is then the one chiefly to be relied upon, not only because it is safer, but also because it gives more information to the examiner, and because it is easier and more reliable. Having for many years practised the vaginal examination exclusively, I found it difficult to persuade myself of the truth of the latter assertion; but not only has my own individual experience proved to me that this is so, but in the Rotunda Hospital, where the students are obliged to write down upon the bedcards the result of each examination, I found that mistakes in diagnosis were much more frequent with the vaginal than with the abdominal method. There are two things, however, which can only be made out by vaginal examination, and these are the condition of the os uteri and a prolapse of the umbilical cord; and if for any reason such as inexperience on the part of the examiner or insuperable difficulties, such as very fat or rigid abdomen on the part of the patient, the results of the abdominal examination are unsatisfactory, a vaginal examination becomes necessary.

\section{INTERNAL Examination.}

But before each internal examination the practitioner should remember that it is an operation never altogether devoid of risk, and he should be fully persuaded in his own mind as to its necessity. For my own part I seldom examine internally more than once in the course of a natural labour, and I endeavour to do so as soon as possible after the full dilatation of the os, as indicated by the rupture of the membranes or a change in the character of the labour pains. I need not delay to describe the disinfection of the hands ; many excellent methods are in vogue, but thoroughness in carrying it out is of more importance than the selection of any particular method; at the same time in general practice it should be simple as well as efficient.

Treatment.

In the treatment of the disease when once established we have also made considerable advances. Local disinfection by antiseptic douching is generally employed, the curette, abdominal section, and ablation of the infected organs have been employed with success, but are hardly in a position for a dogmatic pronouncement upon their value in an address which is not to be followed by discussion. For the same reason I shall not speak of the antistreptococus serum; but the general treatment with which I have met most success, and which is, I believe, now most generally adopted, is that introduced by Runge in 1886, and consists in cool bathing, nourishing diet, avoidance of internal antipyretics, and free administration of alcohol.

\section{Conclusion.}

The subject with which I have dealt is no doubt lacking in novelty, and the method an elaboration of the old saying that " meddlesome midwifery is bad," but I have been urged to its consideration by the opinions expressed by Hegar, Boxall, and Cullingworth, that in private practice there has as yet been no improvement. If this be true, or even partially true, it proves that those who undertake the care of parturient women are not yet alive to the responsibilities of their calling, and I have no doubt that a faithful adherence to the principles, the development of which I have briefly sketched, will result in a vast saving of most valuable lives, and will prevent you individually from standing-as many of us have done in the past-helpless spectators of a fatal malady which an accusing conscience whispers might have been averted.

\section{INTRODUCTORY REMARKS}

DELIVERED AT THE OPENING OF

\section{THE SECTION OF PSYCHOLOGY,}

At the Annual Meeting of the British Medical Association at Ipswich, July-August, 1900.

BY R. PERCY SMITH, M.D., F.R.C.P.,

Lecturer on Psychological Medicine Charing Cross Hospital ; President of the Section

ON THE PREVENTION OF INSANITY.

Probably few circumstances connected with insanity have stirred the public mind more in the last few years than its real or apparent increase. The question is constantly asked by people, Is it not very much on the increase? and it seems to me to be worthy of consideration by this Section of the Association whether we as medical men concerned in the treatment of mental disorders are doing all we can to check what at any rate is a most serious increase in the actual numbers of the insane. As the public owes the checking of the ravages of small-pox, the notification of infectious diseases, the improved sanitary measures which have led to such a marked diminution of the death-rate, and now in all probability the successful coping with the large amount of illness due to malarial poison - to name only a very few instances - to the medical profession, so undoubtedly it will be to the profession that the public will look for guidance in what is undoubtedly a very serious question for the future of our population. The annual report of the Commissioners in Lunacy for the year 1898 (published June, 1899) begins with the remark that the total number of patients under their cognisance in England and Wales on January 1st, 1899, was 105,086, "being an increase on the corresponding number on January 1st, 1898 , of 3,114 , the largest annual increase we have yet had to record." The increase reported by the Commissioners had concerned all classes of patients, the private class to the extent of $\mathbf{2 . 7 3}$ per cent., the pauper class 3.09 per cent., and the criminal class 2 per cent. Of greater importance than the mere fact of increase is the fact that there is also an increase in the ratio of insane to general population, the advance being the small one of 0.4 per cent. in the private class, and of 0.59 per cent. for the pauper class. The total gives the ratio of 1 "officially known" lunatic to 302 individuals, as against 1 in 308 . on January Ist, 1898, and 1 in 337 on January Ist, 1899.

Attempts have been made to show that the increase is more apparent than real, that it is largely due to the accumulation of senile cases and to a diminished death-rate, and that there is no real increase of new cases; but when all is said there remains the undoubted fact that the numbers increase by leaps and bounds, and that the county and borough authorities are constantly being confronted by the demand for more accommodation in county and borough asylums, that new asylums spring up as the result, and that the taxpayer has constantly to put his hand in his pocket to defray expenses. It will hardly be denied that such a condition demands that we should use every effort to diminish if possible at the source the numbers of those who thus become incapacitated either temporarily or permanently, who, if not possessing private means, become either a burden to their relatives or to the taxpayer, and who in some cases become criminals as the result of their mental disorder.

It would be of course quite impossible in the limits of time accorded by the rules of the Association to introductory remarks by Presidents of Sections to review all the causes of insanity and to cover the whole ground of their removal, but it seems to me to be profitable to draw attention to three items-namely:

1. The propagation of the race by those of insane inheritance or those who have suffered from insanity.

2. The influence of alcohol in the production of insanity and the need for preventive legislation.

3. The causation of general paralysis by syphilis. 